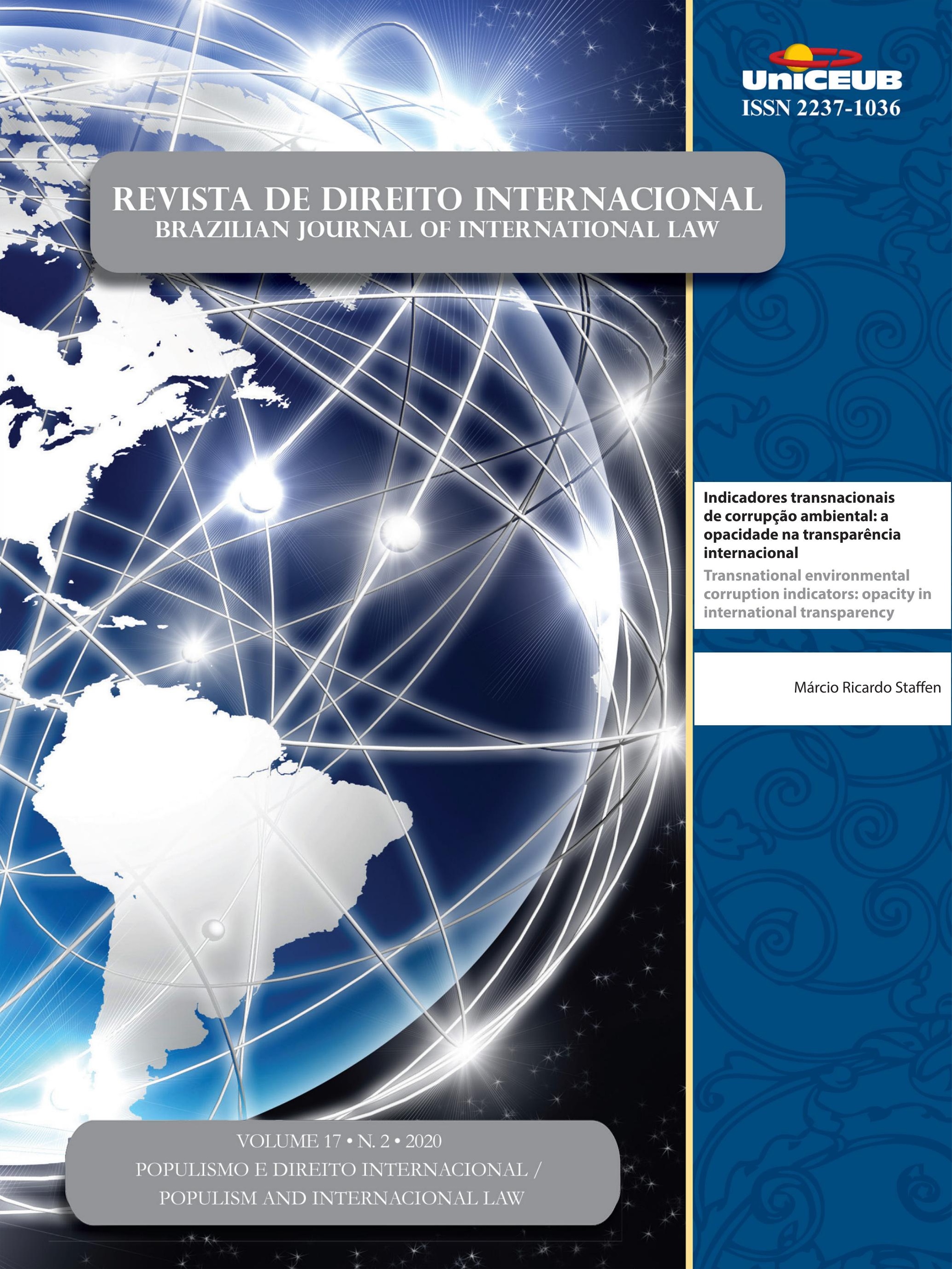




\section{Sumário}

I. CRônicas

A Favor de uma Corte Latino-Americana de Justiça ..................................................... 3 Nitish Monebhurrun

Sobre A SOluÇão JUdicial de CONTROvérsias Na AMÉRICA LATINA 7 Lucas Carlos Lima

A Favor de uma Corte Latino-Americana de Justiça - Uma Reação sobre a Legalidade e A Legitimidade De Seu Desenho Institucional............................................................15

Arthur Roberto Capella Giannattasio

O Estudo do Direito Internacional sob uma Nova Perspectiva: Nossa Experiência na Philip C. Jessup International Moot Court Competition............................................20 Ana Vitória Muniz Bokos, Igor Medeiros Maia, Jefferson Seidy Sonobe Hable, Gabriel de Oliveira Borba, Gilda Nogueira Paes Cambraia e Nayara Lima Rocha Da Cruz

Revisión de laudos de arbitrajes de inversión 2019: I Encuentro Anual (Santiago de

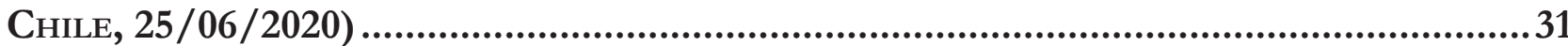
Andrés Delgado Casteleiro e Ivette Esis

II. Dossiê: Populismo e Direito Internacional / Populism and Internatio-

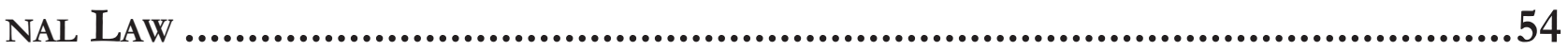

Editorial: Populism and International Law: Global South Perspectives .56 Lucas Lixinski e Fabio Morosini

Editorial: Populismo e Direito Internacional: Perspectivas do Sul Global .61 Lucas Lixinski e Fabio Morosini 
Between Science and populism: the Brazilian Response to COVID-19 from the Perspective of the legal determinants of Global Health

Deisy de Freitas Lima Ventura e Jameson Martins

Populism, ENVIronmental LAW, AND THE POST-PANDEMiC ORDER Alessandra Lehmen

Populism and the Evangelical church in Latin America: how anti-LGBTI forces TRIED TO STOP THE COLOMBIAN PEACE AGREEMENT Julia Assmann de Freitas Macedo e Fabrízio Conte Jacobucci

“Deus EM Davos": o Direito INTERnACIONAL ENTRE REACIONÁRIOS E NEOLIBERAIS NO GOVERNO BOLSONARO 121

Lucas Tasquetto e João Roriz

CHINESE POPULISM IN THE 1920s, EXTRATERRITORIALITY AND INTERNATIONAL LAW 139 Wanshu Cong

CONCEPTUALIZING UNILATERALISM, FRAGMENTATIONISM AND STATISM IN A POPULISM CONTEXT: A RISE OF POPULIST INTERNATIONAL LAW? 162 Wei Shen e Carrie Shu Shang

AUTONOMÍA ADMINISTRATIVA SIN AUTONOMÍA POLÍTICA: LA APLICACIÓN DEL MODELO "UN PAÍS dos SISTEMAs" eN HoNg Kong 186 Juan Enrique Serrano Moreno

III. Artigos sobre outros temas...................................................... 197

Um TWAiler entre nós? As contribuições de Celso Duvivier de Albuquerque Mello PARA O DIREITO INTERNACIONAL (CRÍTICO) NO BRASIL .................................................... 199

Fabio Morosini e Matheus Leichtweis

DEMOCRACIES IN DANGER: ARE JUDICIAL DIALOGUES MEANS TO REFRAIN SETBACKS IN LATIN America?.

Melina Girardi Fachin e Bruna Nowak 


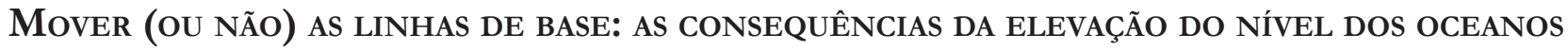
SOBRE AS ZONAS MARÍTIMAS DOS PEQUENOS ESTADOS INSULARES EM DESENVOLVIMENTO E AS ALTERNATIVAS JURÍDICAS PARA REDUZIR SEUS IMPACTOS

Alexandre Pereira da Silva

A mineração em águas profundas no Pacífico 263 Pierre-Jean Bordahandy

Dual Nationality and International Law in times of Globalization. Challenges and Opportunities for Consular Assistance and Diplomatic Protection in RECENT CASES. 288

Walter Arevalo-Ramirez e Robert Joseph Blaise Maclean

Expulsion of aliens: the application of International Law by Chilean Superior Courts 309

Regina Ingrid Díaz Tolosa

O TIPO PENAL BRASILEIRO DE PROMOÇÃo DE MIGRAÇÃO ILEGAL E O PRINCÍPIO DA NÃO CRIMINALIZAÇÃo DA MOBILIDADE HUMANA

Regina Cândido Lima e Silva Santos e Deilton Ribeiro Brasil

INDICADORES TRANSNACIONAIS DE CORRUPÇÃO AMBIENTAL: A OPACIDADE NA TRANSPARÊNCIA INTERNACIONAL

Márcio Ricardo Staffen

SubTRAÇÃo INTERNACIONAL DE CRIANÇAS: ANÁLISE DAS EXCEÇÕES AO RETORNO IMEDIATO DO MENOR À RESIDÊNCIA HABITUAL E CRÍTICA AO ENQUADRAMENTO DA VIOLÊNCIA DOMÉSTICA COMO FLEXIBILIDADE PERMISSIVA

Vivian Daniele Rocha Gabriel

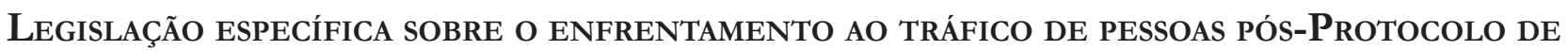
Palermo (2000): análise do Estado de Moçambique 383

Mercia Cardoso de Souza, Guirino Dinis José Nhatave e Francisco Horácio da Silva Frota 
IV. Artigos traduzidos

DIREITO INTERNACIONAL DO RECONHECIMENTO

Emmanuelle Tourme-Jouannet e Tradutor: Ademar Pozzatti Junior

V. RESENHAS

Fabio Costa Morosini, Gabriel Lee Mac Fadden Santos, Valentina Fonseca da Luz e Vinicius Tejadas Maia 


\title{
Indicadores transnacionais de corrupção ambiental: a opacidade na transparência internacional
}

\author{
Transnational environmental corruption \\ indicators: opacity in international \\ transparency
}

Márcio Ricardo Staffen**

\section{Resumo}

O presente artigo objetiva avaliar o grau de mensuração utilizado por indicadores transnacionais de corrupção em relação ao meio ambiente. Para tanto, como referencial da pesquisa, foram investigados os relatórios e documentos técnicos da Transparência Internacional e as abordagens realizadas por essa Organização não Governamental em matéria de corrupção e meio ambiente, especialmente, a mensuração de episódios do gênero nos indicadores transnacionais confeccionados. Assim, a inocorrência de estudos sobre indicadores transnacionais de corrupção ambiental, com foco na Transparência Internacional, dá azo à originalidade da pesquisa, importando em valor acadêmico, uma vez que projeta a opacidade de importante variável para o combate à corrupção. Assim, para o desiderato da pesquisa, restou produzida a síntese de opacidade global, haja vista a ausência de estudos, de projeções e de mensurações sobre o binômio corrupção e meio ambiente, em que pese o reconhecimento de práticas de corrupção em matéria ambiental e os efeitos perniciosos dessa simbiose. Utilizou-se, para o desenvolvimento da presente pesquisa, o método indutivo, operacionalizado pelas técnicas de conceitos operacionais e da pesquisa bibliográfica e documental em relatórios produzidos pela Transparência Internacional, entre os anos de 2017-2020.

Palavras-chave: Transnacionalismo. Indicadores. Corrupção. Meio Ambiente. Transparência.

** Doutor em Direito Público Comparado pela Università degli Studi di Perugia (Itália). Doutor e Mestre em Ciência Jurídica pela Universidade do Vale do Itajaí - UNIVALI. Estágio de Pós-Doutorado em Direito Transnacional - Università degli Studi di Perugia (CAPES/ PDE). Professor nos cursos de Mestrado e Doutorado em Ciência Jurídica - Universidade do Vale do Itajaí. Coordenador e Professor no Programa de Pós-Graduação Stricto Sensu em Direito - Faculdade Meridional/IMED (20142018). Visiting Researcher no Max Planck Institute of Comparative Public Law and International Law (Alemanha). Doutor Honoris Causa pela Universidad Antonio Guillermo Urello (Peru). Professor Honorário da Faculdade de Direito e Ciências Sociais da Universidad Inca Garcilaso de la Vega (Peru). Advogado (OAB/ SC). E-mail: marcio.staffen@gmail.com

\section{Abstract}

This paper aims to assess the degree of measurement used by transnational indicators of corruption in relation to the environment. To this end, as a research reference, the reports and technical documents of Transparency International were investigated and approaches taken by this non-governmental organization in matters of corruption and the environment, especially a measurement of sex display in the transnational indicators produced. Thus, an inoculation of studies on transnational indicators of environmental corruption, focusing on Transparency International, gives rise to the originality 
of the research, importing in the academic value as it projects the opacity of an important variable to fight corruption. Thus, for the research study, you can discover the global display capacity, see, the absence of studies, the projections and measurements on the binomial of corruption and the environment, in which case the resource of chemistry practices in environments environmental effects and the harmful effects of this symbiosis. For the development of this research, the inductive method was used, made operational by the techniques of operational concepts and bibliographic and documentary research in reports published by Transparency International, between the years 2017-2020.

Keywords: Transnationalism. Indicators. Corruption. Environment. Transparency.

\section{Introdução}

O presente artigo objetiva avaliar o grau de mensuração utilizado por indicadores transnacionais de corrupção em relação ao meio ambiente, afinal, a escassez de recursos, a burocracia estatal, a especulação econômica, as condições sociais e financeiras induzem atos de corrupção relacionados com o meio ambiente e seus sistemas, seja em Estados em desenvolvimento, seja em Estados desenvolvidos.

Sem prejuízo de questões igualmente complexas, o decurso da última metade de século tornou recorrente, nos espaços de debate político, público e/ou privado, discussões sobre casos de danos e desastres ambientais, bem como a reiteração de escândalos de corrupção, sem que se possa atestar a condição local desses episódios.

Cumulativamente, com a efetiva ampliação de redes de comunicação, deslocamento e interdependência sistêmica, que configura a noção de globalização, os casos de corrupção e violação da proteção ambiental ganharam relevância em nível transnacional e global, exigindo, inclusive, das instituições jurídico-políticas, respostas eficazes para o combate aos danos ambientais e à corrupção.

Assim, autonomia nacional, em questões políticas, sociais, econômicas e também jurídicas, para os problemas ambientais e de integridade, é, cada vez mais, limitada pelas interdependências políticas, econômicas e de governance entre os Estados e a regulamentação em nível global, configurando hipótese de atuação para a face jurídica da globalização.

Paralelamente, o fenômeno da globalização jurídica, a progressiva implementação de práticas de governance e a utilização de variados indicadores, rankings, índices e observatórios produziu uma combinação de autonomia política limitada em nível nacional e a tomada de decisão, cada vez mais executiva, sobre regimes especializados no nível transnacional, alterando os fundamentos clássicos da deliberação política, da democracia e das fontes do direito, ao tempo em que a esfera nacional resta altamente porosa para demandas e exigências transnacionais/globais.

Há tempo o caso brasileiro de prevenção ambiental e combate à corrupção, associado à promoção de práticas de transparência, é reflexo de pressões transnacionais que se sobrepõem às resistências e divergências internamente articuladas ${ }^{1}$. Nesse sentido, ao tempo em que a ascendência substancial de indicadores e demais meios de governance preencheu espaços e realocou modelos tradicionais de combate e prevenção à corrupção, em relação à tutela do meio ambiente, não se observa igual fenômeno.

Como hipótese de pesquisa, portanto, levanta-se presença de opacidade existente no âmbito dos indicadores, relatórios e documentos técnicos da Transparência Internacional em relação à junção de corrupção e meio ambiente. Justifica-se a eleição da Transparência Internacional, haja vista sua destacada condição em cenário global, a sequência ininterrupta de seus estudos e a prestigiosa atuação que exerce.

Consignam-se como problemas para a pesquisa: a) é possível verificar, no teor dos indicadores de corrupção produzidos pela Transparência Internacional, métricas de avaliação sobre meio ambiente e governance ambiental? b) A ausência de métricas de avaliação sobre meio ambiente e corrupção constitui seletividade em bens jurídicos correlatos, descalcificando a eficácia e a efetividade das propostas apresentadas pela Transparência Internacional?

No que tange à metodologia, utilizou-se, para o desenvolvimento da presente pesquisa, o método induti-

\footnotetext{
Para maiores comparações: STAFFEN, Márcio Ricardo; OLIVIERO, Maurizio. Transparência enquanto pretensão jurídica global. A \& C - Revista de Direito Administrativo \& Constitucional, Belo Horizonte, v. 15, n. 61, p. 71-91, jul-out. 2015; VANNUCCI, Alberto. Atlante della corruzione. Torino: Le Staffete, 2012. p. 111.
} 
vo, operacionalizado pelas técnicas de conceitos operacionais e da pesquisa bibliográfica e documental em relatórios produzidos pela Transparência Internacional, entre os anos de 2017-2020.

\section{Meio ambiente e corrupção na pauta institucional transnacional}

A recorrência de acontecimentos de crises econômicas, políticas, ambientais, sanitárias, humanitárias, energéticas, bem como da ascensão de riscos advindos com a ameaça terrorista e com a corrupção sistêmica acelerou a formação de aglomerados policêntricos para gestão e regulação de manifestações transfronteiriças. Noutro lado, o desenvolvimento acelerado de novas tecnologias, bens e serviços, fez com que a normatização incidente sobre estes partisse de fluxos distintos dos estatais ${ }^{2}$.

Invariavelmente, tais fluxos correspondem ao cenário de crises e de demandas que se consolidaram desde pautas reais de reivindicação frente a problemas peculiares. Do caso Hiroshima/Nagasaki ao caso Chernobyl; do caso Exxon Valdez ao caso Bhopal; do caso Brumadinho ao caso Hoffmann-La Roche, ambos introduziram, na comunidade mundial, a percepção dos riscos à vida humana, desde reiteradas degradações ao meio ambiente, com capacidade para transposição de fronteiras, nacionalidade e cidadania.

Por sendas similares, o conhecimento de escândalos de corrupção na Tangentopoli, iniciada na Itália; na Lava-Jato, originária do Brasil; na FIFA, sediada na Suíça; nas federações desportivas, vinculadas com a Rússia; no Dieselgate, a partir dos Estados Unidos; do Panamá papers, advindos do Panamá e; do Vatileaks, com centro no Vaticano, por exemplo, deslocou a necessidade de comba-

\footnotetext{
2 Ainda que trabalhando com a Teoria de Regimes Jurídicos, merece destaque os argumentos de Salem Hikmat Nasser: "Regimes jurídicos transnacionais, para serem jurídicos, ou devem pressupor uma definição de direito diferente, de modo a diferenciá-los do que faz jurídicos os regimes que fazem parte do direito internacional público, ou devem pressupor uma definição ampliada, mais inclusiva, que possa abarcar ambos tipos de conjuntos de normas, regras etc. Num mesmo fôlego, direito do comércio internacional, direito do meio ambiente, lex mercatoria, lex constructionis, lex digitalis, são oferecidos como exemplos desses regimes funcionais que seriam a expressão da fragmentação do direito global". NASSER, Salem Hikmat. Direito global em pedaços: fragmentação, regimes e pluralismo. Revista de Direito Internacional, Brasília, v. 12, n. 2, p. 104, 2015.
}

te e prevenção à corrupção da pauta penal dos Estados para acordos, instituições e atores transnacionais.

Como consequência, a alocação da defesa do meio ambiente e do combate à corrupção como pautas de atores e instituições transnacionais fez surgir, a partir do contexto de preocupações compartilhadas, organizações interessadas especificamente nos mencionados problemas, seja para denunciação, seja para prevenção, ou para articulação institucional. Essas organizações circulam, globalmente, sem atrelamento direto com governos nacionais, impactando, substancialmente, cada ordenamento jurídico nacional.

Esse diagnóstico representa o exaurimento do Estado e das instituições internacionais de cunho monista-dualista ${ }^{3}$, tal qual havia previsto Philip Jessup, porém com engrenagens muito mais consistentes daquelas previstas em meados de $1950^{4}$. As vertentes do Direito (nacional, internacional e global) articulam-se em múltiplos níveis, governos, administrações locais, instituições intergovernamentais, cortes ultraestatais e nacionais, networks, organismos híbridos (público-privado), Organizações não Governamentais e dos próprios indivíduos.

Os atos de globalização do jurídico propiciam instrumentos para o estabelecimento de canais de abertura e interpenetração dos preceitos normativos exarados por múltiplos agentes de cunho público e/ou privado, que, além do contributo na produção da norma, diante do poder que concentram, exercem atribuições de controle e correição, juntamente ou em substituição das funções burocráticas estatais ${ }^{5}$. Exatamente pela envergadura que possui tal poder, as proposições de modelos jurídicos são essenciais para sua submissão.

\footnotetext{
Conforme Armin von Bogdandy: "They also lead into a dead end from the point of view of theories designed to capture the entire legal constellation, both analytically and normatively. Dualism ultimately shares the fate of the traditional principle of sovereignty. Monism with public international law at its apex shares the weaknesses of world constitutionalism as a paradigm for grasping the existing law." VON BOGDANDY, Armin. Common principles for a plurality of orders: A study on public authority in the European legal area. International Journal of Constitutional Law, Oxford, v. 12, n. 4, p. 1005, out. 2014.

4 "I shall use, instead of 'international law', the term 'transnational law' to include all law which regulates actions or events that transcend national frontiers. Both public and private international law are included, as are other rules which do not wholly fit into such standard categories" JESSUP, Philip. Transnational law. New Haven: Yale University Press, 1956. p. 136.

5 STAFFEN, Márcio Ricardo. Superlegality, global law and the transnational corruption combat. Revista Brasileira de Direito, v. 14, n. 1, p. 111-130, abr. 2018.
} 
Por linhas similares avança a posição de Harold Koh, para quem o processo de transnacionalização do Direito ganha corpo a partir da complementariedade de atuação dos atores responsáveis por ativar o processo (transnational norm entrepreneurs) juntamente aos apoiadores governamentais (governmental norm sponsors), os quais, em conjunto, desenvolvem padrões normativos de cunho transnacional/global. ${ }^{6}$

Em linhas gerais, a globalização promove uma radical mudança nos poderes em operação nos mais diversos níveis, incluindo o poder ideológico, institucional e normativo, com as respectivas interações sociais que, a todo momento, encontram novos arranjos. O poderio dos ordenamentos jurídicos estatais, portanto, de produzir e também de aplicar seu próprio Direito em forma absoluta, está, gradualmente, se redimensionando, reformulando a própria categoria histórica e política da soberania nacional na direção de uma caracterização, ainda, de híbrida matriz.

Esse cenário de cooperação, absolutamente novo em suas características, pode ser facilmente ilustrado nos exemplos da Organização Internacional para a Estandardização (ISO), composta por organismos de normatização, de matriz híbrida público-privado, criando pontes entre setores públicos e privados, mas, com atribuições, regulamentadoras iminentemente públicas ${ }^{7}$. O mesmo critério de parceria vislumbra-se com a aderência de Estados ao Comitê da Basileia para vigilância bancária, de modo que uma instituição tipicamente nacional transcende sua prima ratio para contribuir com autoridades bancárias internacionais. Outro caso de envergadura e incidência prática no dia a dia aponta para a regulamentação e regulação da internet. Cabe à ICANN - Internet Corporation for Assigned Names and Numbers, uma organização público-privada, composta por entes privados, desenvolver funções públicas que atingem o globo indistintamente.

$\mathrm{Na}$ mesma toada, por sua vez, existem organizações estritamente privadas a transitarem no cenário global sem pontos de dependência e condicionantes público-estatais. É o caso do Comitê Internacional de Estandares Contábeis (IASB), da Agência Mundial Antidopa-

${ }^{6} \mathrm{KOH}$, Harold Hongju. Why Transnational Law Matters. Faculty Scholarship Series, 2006, paper 1793. Disponível em: http://digitalcommons.law.yale.edu/fss_papers/1793 Acesso em: 20 maio 2017.

SCHEPEL, Harm. The constitution of private governance: product standards of integrating markets. Oxford: Hart, 2005. gem (WADA), da Comissão Eletrotécnica Internacional (IEC) e da Câmara Internacional de Comércio (ICC), que elaboram e aplicam suas normas de modo autônomo com o objetivo central de promover o comércio e investimentos internacionais, servindo, inclusive, de instituição parceira para organismos nacionais e internacionais, conforme se vislumbra com a ONU e com a $\mathrm{OMC}^{8}$. Por sua vez, não são raras as instituições que operam em cenários globais exercendo, no âmbito de suas atividades, monopólios normativos e/ou fiscalizatórios, condicionando, inclusive Estados, suas instituições e as organizações internacionais. ${ }^{\text {? }}$

Ademais, observa-se progressiva majoração de organizações privadas na tratativa de assuntos globais, com gerência regulamentadora e reguladora, nas mais diversas áreas de incidência e de competência material. Dentre estas, entes originariamente privados, sem vínculos governamentais, que se dedicam à proteção ambiental, ao controle da pesca, à fruição dos direitos sobre a água, à segurança alimentar, ao combate da corrupção, às finanças e o comércio, à internet, aos fármacos, à tutela da propriedade intelectual, à proteção de refugiados, à certificação de insumos quanto à procedência, à preservação da concorrência, ao controle de armas e combate ao terrorismo, ao transporte aéreo e naval, aos serviços postais, às telecomunicações, à energia nuclear e seus resíduos, à instrução, à imigração, à saúde e ao esporte.

Por tais linhas, pautas locais de combate à corrupção e aos danos ambientais ganharam relevo e luzes em níveis transnacionais, assumindo, destarte, contornos globais, fazendo reduzir espaços de opacidade e velamento. De um lado, tal situação é consequência do fenômeno da globalização sistêmica e multifacetada experimentada desde a segunda quadra do século XX. Sobre outro viés, a transcendência local é resultado da verificação da impotência dos meios locais de prevenção, contenção e punição de ocorrências de corrupção e violações ecológico-ambientais.

Entretanto, não obstante o surgimento de instituições transnacionais hábeis ao enfrentamento de cada tema em específico, o grau de desenvolvimento e complexidade dos respectivos fenômenos deman-

8 CASSESE, Sabino. Chi governa il mondo? Bologna: Il Mulino, 2013. p. 19.

9 DARNACUlLETA I GARDELLA, Maria Mercè. El derecho administrativo global. Un nuevo concepto clave del derecho administrativo? Revista de Administración Pública, Madrid, n. 199, enero-abril, p. 25, 2016. 
dou padrões métricos de comparação, padronização e especificação de incidência global, induzindo, assim, a utilização de indicadores transnacionais para satisfação das demandas emergentes sem a dependência de expedientes nacionais. Em síntese, a função de indicadores transnacionais concentra-se na ideia de padronização técnica, comparação transnacional e transparência em nível global, de tópicos de interesses difusos, tal qual o meio ambiente e a corrupção.

\section{0 sentido e o limite no uso de indicadores transnacionais}

Notadamente os processos de globalização, de maneira crescente, criaram um território mundial - uma nova ordem supra e transnacional que permite circulação de pessoas, ideologias, capitais, mercadorias, bens e serviços -, o qual demonstra a redução (crise) do Estado e institui instrumentos de governança global. Nas palavras de Armin von Bogdandy ${ }^{10}$, a internacionalização se tornou um modo de vida.

Com isso, a prática de produção e o uso de indicadores na governança global estão em constante ampliação e sofisticação. De um lado, atores transnacionais, como as agências de classificação de riscos; agências públicas de desenvolvimento internacional, como o Banco Mundial e as Nações Unidas; organismos governamentais de ajuda, como a Corporação do Desafio do Milênio, empresas globais e investidores; órgãos preocupados em avaliar ou fazer cumprir os padrões legais existentes, como órgãos de monitoramento de tratados de Direitos Humanos, ONGs e várias comunidades científicas ou especializadas, principalmente no campo da ciência política, sistematicamente utilizam e promovem métricas especializadas de comparação e desempenho ${ }^{11}$.

Noutro lado, a publicação e circulação global de indicadores, rankings, índices e afins infiltra-se, também,

\footnotetext{
10 VON BOGDANDY, Armin. Common principles for a plurality of orders: A study on public authority in the European legal area. International Journal of Constitutional Law, Oxford, v. 12, n. 4, p. 890, out. 2014.

11 DAVIS, Kevin E; KINGSBURY, Benedict; MERRY, Sally Engle. Introduction: global governance by indicator. In: DAVIS, Kevin E; KINGSBURY, Benedict; MERRY, Sally Engle. Governance by indicators. Global power through qualification and rankings. Oxford: Oxford University Press, 2012. p. 03.
}

sobre temas e demandas nacionais/locais ${ }^{12}$. Seja pelo afã de promover comparações, por imposições advindas de contratos de investimento e/ou pelo anseio de maior legitimidade das decisões produzidas, o uso de indicadores transnacionais/globais avança no território até então controlado pela política e pela burocracia soberana dos Estados.

Nesse sentido, a utilização de indicadores de governança, em que pese sua gênese transnacional com maior frequência e densidade, condicionam expedientes nacionais desde fora; à distância, porém com sagacidade. O Controle da Corrupção e "rule of law", produzido pelo Banco Mundial; os indicadores dos Objetivos de Desenvolvimento do Milênio sob os auspícios da ONU; o Índice de Percepção de Corrupção desenvolvido pela Transparency International ${ }^{13}$; o Índice de Desenvolvimento Humano (IDH) produzido pelo Programa das Nações Unidas para o Desenvolvimento (PNUD); os indicadores de Tráfico de Pessoas publicados pelo Departamento de Estado dos EUA; o ranking PISA de aproveitamento escolar confeccionado pela Organização para Cooperação ao Desenvolvimento Econômico $(\mathrm{OCDE})^{14}$ e vários indicadores produzidos por consultorias especializadas em assessorar os investidores em riscos políticos, podem ser elencados como exemplos dessa nova tendência global ${ }^{15}$.

A crescente produção e uso de indicadores na governança global têm o potencial de alterar as formas, o exercício e, talvez, até as distribuições de poder em certas esferas de governança global ${ }^{16}$. Em linhas ge-

12 VILLAGRAN SANDOVAL, Carlos Arturo. Soberanía y legitimidad de los actores internacionales en la reforma constitucional de Guatemala. Política Internacional, Ciudad de Guatemala, v. 1, a. 1, p. 34-57, junio 2016. p. 39-40.

13 STAFFEN, Márcio Ricardo; OLIVIERO, Maurizio. Transparência enquanto pretensão jurídica global. $A \& C$ - Revista de Direito Administrativo \& Constitucional, Belo Horizonte, v. 15, n. 61, jul-out. p. 71-91, 2015.

14 VON BOGDANDY, Armin; GOLDMANN, Mathias. Taming and framing indicators: a legal reconstruction of the OECD's Programme for International Student Assessment (PISA). In: DAVIS, Kevin E; KINGSBURY, Benedict; MERRY, Sally Engle. Governance by indicators. Global power through qualification and rankings. Oxford: Oxford University Press, 2012. p. 52 ss.

15 DAVIS, Kevin E; KINGSBURY, Benedict; MERRY, Sally Engle. Introduction: global governance by indicator. In: DAVIS, Kevin E; KINGSBURY, Benedict; MERRY, Sally Engle. Governance by indicators. Global power through qualification and rankings. Oxford: Oxford University Press, 2012. p. 03-04.

16 DAVIS, Kevin E; KINGSBURY, Benedict; MERRY, Sally Engle. Introduction: global governance by indicator. In: DAVIS, Kevin E; KINGSBURY, Benedict; MERRY, Sally Engle. Governance by in- 
rais, o uso de indicadores de governança sinaliza o grau de especialização conquistado em nível global ${ }^{17}$. Ao seu tempo, avança em sua capacidade de penetrar no exercício de políticas públicas, investimentos, processo legislativo, atuação judicial e organização social também nos assuntos domésticos de cada Estado.

Assim, a circulação e utilização de indicadores não se demarca, perfeitamente, entre o nacional, o internacional e o global. Seja para a avaliação dos impactos transnacionais quanto influências nacionais, os mecanismos carecem de iluminação diversa do estadocentrismo ou monismo/dualismo. Os mecanismos orientados pelo Direito Internacional, em igual medida, restam topograficamente confusos, haja vista a multiplicação de normatizações internacionais informais, pois muitas normas internacionais recentemente editadas não se configuram como tratados formais ${ }^{18}$. Os indicadores globais de governança, são globais em relação ao ente responsável pela sua produção e pela comparação que produzem, mas transitam nos espaços nacionais para condicionarem demandas locais sem deixarem de ser globais.

Conforme diagnostica Saskia Sassen, o momento atual da autoridade e do Direito é marcado pela justaposição de territórios e de poderes que se movem rapidamente graças ao domínio e a produção da informação. Para se evitar as chamadas "fracturas en la regulación", as políticas de regulação nacionais buscam evitar o rótulo de descumprimento normativo, o vazio legislativo e/ou a desconformidade das normas com oferta de mecanismos alinhados com as demandas de atores nacionais $\mathrm{e}$ globais, de modo que o local, enquanto orientado pelo global, é ponto elementar para dar funcionamento deste (o global $)^{19}$.

Diante desse cenário de justaposição e de penetração nos assuntos nacionais, a invocação de indicadores de governança global necessita vir acompanhada de

dicators. Global power through qualification and rankings. Oxford: Oxford University Press, 2012. p. 04.

17 DARNACULLETA I GARDELLA, Maria Mercè. Autorregulación y derecho público: la autorregulación regulada. Madrid: Marcial Pons, 2005. p. 63.

18 PAUWELYN, Joost. Informal international lawmaking: framing the concep and research questions. In: PAUWELYN, Joost; WESSEL, Ramses; WOUTERS, Jan. Informal international lawmaking. Oxford: Oxford University Press, 2012. p. 13 ss.

19 SASSEN, Saskia. Territorio, autoridad y derechos. De los ensamblajes medievales a los ensamblajes globales. Buenos Aires: Katz, 2015. p. 488-493. questionamentos para além do juízo de conveniência e oportunidade. Seguindo a proposta de Davis Kevin, Benedict Kingsbury e Sally Merry, a respeito da utilização de indicadores em processos nacionais, perpassa saber: quais processos sociais envolvem a criação e o uso de indicadores? Como as condições de produção influenciam os tipos de conhecimento, mudam a natureza da definição de padrões e da tomada de decisão? Como isso afeta a distribuição do poder entre os que governam e aqueles que são governados? Qual é a natureza das respostas aos exercícios de poder por meio de indicadores, incluindo formas de contestação e tentativas de regular a produção ou uso de indicadores? ${ }^{20}$.

Considerando-se as particularidades de cada regime democrático nacional e, noutro ponto, as especificidades dos indicadores de governança global, a saber: simplificação de dados brutos e do complexo social; comparação com demais padrões e entes; recorte temporal sobre dados e fatos e; a autoridade científica-técnica dos responsáveis por sua produção, necessário se faz uma filtragem na adoção e na mensuração da extensão do uso para os indicadores.

A mera validação e/ou referência aos indicadores propicia o encampamento de questões políticas, institucionais e jurídicas sensíveis. Embora, tradicionalmente, cada indicador receba uma nomenclatura alinhada com sua síntese de dados ou da sua pretensão de classificação, apenas isso não justifica o seu uso. Nesse sentido, há de se considerar que corrupção e transparência estão consubstanciadas na lógica da mensuração estatística.

Na mesma linha de parcimoniosa utilização dos indicadores, há de se pontuar a necessidade de atenção aos métodos e expedientes de comparação. Todo indicador é resultado de uma simplificação do complexo social que carece de comparação entre cada estrutura em análise ${ }^{21}$. Portanto, introduzir, no discurso nacional,

${ }^{20}$ DAVIS, Kevin E; KINGSBURY, Benedict; MERRY, Sally Engle. Introduction: global governance by indicator. In: DAVIS, Kevin E; KINGSBURY, Benedict; MERRY, Sally Engle. Governance by indicators. Global power through qualification and rankings. Oxford: Oxford University Press, 2012. p. 04. No original: "What social processes surround the creation and use of indicators?, How do the conditions of production influence the kinds of knowledge change the nature of standard-setting and decision-making?, How does it affect the distribution of power between and among those who govern and those who are governed?, What is the nature of responses to the exercises of power through indicators, including forms of contestation and attempts to regulate the production or use of indicators?".

${ }^{21}$ DAVIS, Kevin E; KINGSBURY, Benedict; MERRY, Sally En- 
indicadores de governança global, sem a devida exposição comparada, esvazia o conteúdo do debate político-institucional ${ }^{22}$. O uso de indicadores como ideia de Direito público necessita especificar, em sociedades democráticas, as condições e o exercício de tal poder. ${ }^{23}$

Como resultado, a utilização de argumentos dotados de indicadores de governança global, sem a devida adequação e compatibilidade, além de solapar o exercício de faculdades democráticas substanciais, desconsidera a natureza específica e comparada dos indicadores para usá-los como argumento de autoridade. Consequentemente, a natureza da resposta entre a demanda e a natureza do poder é desconsiderada perante a noção de legitimação pré-determinada inerente a cada indicador. Destarte, no plano nacional, assume-se o risco de colocar a autoridade da informação como paralela à autoridade de seus manipuladores na hierarquia ${ }^{24}$, qualitativamente prejudicando tanto o debate democrático quanto a destinação dos indicadores.

Há de se consignar que indicadores são frequentemente utilizados em espaços nacionais de normatização pela carga de eficiência, consistência, transparência, cientificidade e imparcialidade ${ }^{25}$. Com frequência o labor de compilação de indicadores de governança global para projetos de lei se orienta pela economia que tais atributos conferem ao expediente de subsidiar cada

gle. Introduction: global governance by indicator. In: DAVIS, Kevin E; KINGSBURY, Benedict; MERRY, Sally Engle. Governance by indicators. Global power through qualification and rankings. Oxford: Oxford University Press, 2012. p. 08.

22 ESPELAND, Wendy Nelson; SAUDER, Michael. The dynamism of indicators. DAVIS, Kevin E; KINGSBURY, Benedict; MERRY, Sally Engle. Governance by indicators. Global power through qualification and rankings. Oxford: Oxford University Press, 2012. p. 87.

23 VON BOGDANDY, Armin; GOLDMANN, Mathias. Taming and framing indicators: a legal reconstruction of the OECD's Programme for International Student Assessment (PISA). In: DAVIS, Kevin E; KINGSBURY, Benedict; MERRY, Sally Engle. Governance by indicators. Global power through qualification and rankings. Oxford: Oxford University Press, 2012. p. 53.

24 DAVIS, Kevin E; KINGSBURY, Benedict; MERRY, Sally Engle. Introduction: global governance by indicator. In: DAVIS, Kevin E; KINGSBURY, Benedict; MERRY, Sally Engle. Governance by indicators. Global power through qualification and rankings. Oxford: Oxford University Press, 2012. p. 09, no original: "The authority of the information parallels the authority of its handlers in the hierarchy."

25 DAVIS, Kevin E; KINGSBURY, Benedict; MERRY, Sally Engle. Introduction: global governance by indicator. In: DAVIS, Kevin E; KINGSBURY, Benedict; MERRY, Sally Engle. Governance by indicators. Global power through qualification and rankings. Oxford: Oxford University Press, 2012. p. 16. $\operatorname{proposta}^{26}$.

Tal constatação decorre de dois pontos básicos. O primeiro associado a máxima de que os indicadores são padrões e, portanto, carecem de reflexões e avaliações sobre sua plena utilização em um contexto específico de comparação e alteração. O segundo vincula-se com a crescente utilização de indicadores de governança global para suplantar vácuos ou adequar espaços ideológicos para uma sociedade melhor, por instituições adequadas, aproximando uma boa sociedade com uma boa política. ${ }^{27}$

Face à influência de indicadores de governança global, o uso de indicadores requer constante confrontação à compatibilidade social, aos fenômenos de alteração, à natureza do poder a ser exercido e ao grau de interferência. A validação de indicadores apenas por deferência às autoridades transnacionais ou como instrumento ideológico tende a esvaziar e comprometer o resultado normativo produzido ${ }^{28}$. Indicadores podem auxiliar o Estado Democrático de Direito, mas não devem ser adotados como um argumento e/ou ideologia prêt-à-porter que a tudo justifica.

\section{Opacidade e indicadores transnacionais de combate à corrupção e ambiente: 0 caso da transparência internacional}

Atores globais exercem forte pressão nos poderes soberanos nacionais para introduzirem mecanismos preventivos e repressivos de combate à corrupção. Nesses casos, o Legislativo e o Executivo convertem-se em destinatários de "recomendações" provenientes do exterior, para adequarem suas normatizações e regulamentos que atingem, também, o Judiciário. No Brasil, exemplificativamente, é clara a menção nas exposições

26 STAFFEN, Márcio Ricardo. Legislar por indicadores: a iniciativa legislativa brasileira anticorrupção conforme a influência de atores transnacionais. Revista de Informação Legislativa, Brasília, DF, v. 56, n. 221, p. 169-193, jan./mar. 2019.

27 DAVIS, Kevin E; KINGSBURY, Benedict; MERRY, Sally Engle. Introduction: global governance by indicator. In: DAVIS, Kevin E; KINGSBURY, Benedict; MERRY, Sally Engle. Governance by indicators. Global power through qualification and rankings. Oxford: Oxford University Press, 2012. p. 09.

28 CATANIA, Alfonso. Metamorfosi del diritto. Decisione e norma nell'età globale. Roma-Bari: Laterza, 2010. p. 10 ss. 
de motivos de projetos de leis (sentido lato) de combate à corrupção, subsidiados por indicadores, rankings, memorandos e estatísticas de organizações como Banco Mundial, Transparência Internacional, Comitê da Basileia, GAFI, ONGs e Fundo Monetário Internacional ${ }^{29}$.

Contudo, nenhuma instituição de espraiamento global na matéria de combate à corrupção e promoção de transparência é tão atuante quanto a Transparência Internacional. Essa Organização não Governamental, nascida na Alemanha, nos idos de 1980, conquistou posição hegemônica em nível global ao trazer, substancialmente, para o centro do debate político, temas relacionados à corrupção e à transparência por meio de métricas de comparação com outros Estados, anualmente tabuladas.

Mesmo com a recente preocupação da Organização das Nações Unidas e seus organismos com os temas nucleares da Transparência Internacional, é esta a instituição de maior incidência, impactando governos soberanos, empresas privadas, atividade legislativa e judiciária, nacional e internacional, detendo, inclusive, status participativo na ONU. Seus relatórios, índices e rankings contracenam em impacto e recorrência com documentos como as Convenções de Mérida e de Palermo.

Em comum, os relatórios, índices e rankings produzidos pela Transparência Internacional retratam e transparecem os modos pelos quais a corrupção se instala, se espraia e se camufla em cada realidade nacional, desde a realidade local e avaliados por métricas globais ${ }^{30}$. De modo complementar, a mencionada ONG prospecta a percepção popular sobre a corrupção e, doutro lado, a incidência da corrupção por grupos de instituições públicas e/ou privadas.

Com o desiderato de construir um espaço motiva-

\footnotetext{
29 Apenas para ilustrar as normas publicadas nos últimos 10 anos, a partir da realidade brasileira, é possível apontar como exemplos diretos dessa otimização da atividade legiferante, com o acoplamento recomendações transnacionais: Lei Complementar 131/2009 (Lei da Transparência) e Lei 12.527/2011 (Lei de Acesso Público à Informação), influência direta dos preceitos da ONG Transparência Internacional; Lei 12.846/2013 (Lei Anticorrupção), influência da ONG Transparência Internacional, Banco Mundial e convenções da ONU; Lei 13.260/2016 (Lei Antiterrorismo), influência direta do GAFI, mediante memorandos, para controle de movimentações financeiras para suporte a grupos terroristas; Lei 13.322/2016 (Lei Antidopagem), adota prescrições da WADA para fins de controle sobre o uso de substâncias proibidas para prática desportiva.

30 TRANSPARÊNCIA Internacional. Índice de Percepção da Corrupção. Brasil. 2019. Disponível em: https://ipc2019.transparenciainternacional.org.br/. Acesso em: 23 fev. 2020.
}

cional global para engajamento contra a corrupção, a Transparência Internacional expressa seu propósito de dar poder às pessoas, à sociedade civil, às organizações não governamentais e à mídia para denunciar suspeitas e casos de corrupção, em favor do acesso a direitos e à cidadania, avaliando os esforços locais com "as melhores experiências internacionais", conforme se extrai do Relatório Bianual 2017-2018 ${ }^{31}$. Assim, a atuação da Transparência Internacional foca em comportamentos, leis e instituições.

A confluência desses fatores, matematizados por meio de métricas específicas, registram que $85 \%$ da população da América Latina e do Caribe observa na corrupção um grande problema. No mesmo instrumento, $53 \%$ das pessoas entrevistadas afirmaram perceber um aumento na corrupção nos últimos doze meses. Na sequência, registrou o Barômetro Global da Corrupção, produzido pela Transparência Internacional em 2019, como lócus gravitacional da corrupção, o setor político. ${ }^{32}$

Desse contexto que emerge o paradoxo da opacidade dos indicadores transnacionais da Transparência Internacional em sede de combate à corrupção, pois induz referenciais canalizados para comportamentos, leis e instituições sob o viés seletivo direcionado aos mandatários dos governos estatais, aos congressistas, aos partidos políticos e aos tribunais, mesmo produzindo em 2006 o relatório "Corruption and Environmental"33. No contexto da América Latina e Caribe, quando a população responde confiar mais em banqueiros, líderes religiosos, organizações não governamentais e executivos, em comparação a magistrados, polícia, vereadores, oficiais de governo, ministros e presidentes/primeiros-ministros, há um sinal inequívoco de direcionamento do tipo de corrupção combatido ${ }^{34}$ e da necessidade de

TRANSPARÊNCIA Internacional. Relatório Bianual 20172018. Disponível em: https://transparenciainternacional.org.br/ home/relatorio-bianual-2017-2018. Acesso em: 08 mar. 2020.

32 TRANSPARÊNCIA Internacional. Barômetro Global da Corrupção. América Latina e Caribe 2019. Disponível em: https:// comunidade.transparenciainternacional.org.br/asset/54:bgc--barometro-global-da-corrupcao-2019?stream=1. Acesso em 01 mar. 2020.

33 LEITÃO, Alexandra. Corruption and environmental. Journal of Socialomics, v. 5, n. 03, p. 02-03, jun. 2016.

34 Em países como Venezuela, Peru, Colômbia, Guatemala e El Salvador, aproximadamente $90 \%$ da população entrevistada admite não confiar nos seus Tribunais, na Polícia e nos Governos. TRANSPARÊNCIA Internacional. Barômetro Global da Corrupção. América Latina e Caribe 2019. Disponível em: https:/ / comunidade.transparenciainternacional.org.br/asset/54:bgc---barometroglobal-da-corrupcao-2019?stream=1. Acesso em: 01 mar. 2020. 
melhoria. Há de se afirmar que tal opacidade está vinculada à ausência de delineamento do fenômeno da corrupção e seu sentido legal.

Ao tempo em que a corrupção fragiliza o direito a ter direitos, que compromete o funcionamento dos poderes públicos e priva a noção de desenvolvimento, por outro lado, não se pode objetivar sintetizar a solução dos problemas, especialmente nos países da América Latina e Caribe, no sistema político (políticos e partidos políticos) ${ }^{35}$. Criar uma visão míope e seletiva para o problema implica a potencialização de crises e descalcificação das instituições político-jurídicas.

Há miopia e seletividade, especialmente no contexto da América Latina e Caribe, cenário de inquestionáveis riquezas naturais e de injustiças sociais potencializadas pelos obstáculos de acesso efetivo a serviços públicos básicos, quando os relatórios, indicadores, rankings e documentos da Transparência Internacional não incluem a relação entre corrupção e bens/serviços ambientais ${ }^{36}$.

Dos relatórios, indicadores, rankings e documentos da Transparência Internacional, produzidos a partir de 2016, especificamente nenhum deles avalia o quando o acesso a bens e serviços ambientais é impulsionador de práticas de corrupção, suborno e lavagem de dinheiro, envolvendo segmentos da iniciativa privada e órgãos públicos. Não se trata, apenas, de vislumbrar práticas omissivas/comissivas que, a partir de vantagens de muitas espécies, flexibilizam exigências de licenciamento, uso e fiscalização sobre bens ambientais ou, de cenários de desastres ambientais em que sua ocorrência poderia ser mitigada ou evitada.

\footnotetext{
35 "A falta de integridade política pode enfraquecer a base democrática em vários países da América Latina e do Caribe. Isso pode ser visto em abusos nos processos eleitorais, tais como a compra de votos e a disseminação de fake news (notícias falsas), e no enfraquecimento de instituições. O aumento da desconfiança e decepção com o governo tem contribuído para um sentimento anticorrupção maior em toda a região." TRANSPARÊNCIA Internacional. Barômetro Global da Corrupção. América Latina e Caribe 2019. Disponível em: https://comunidade.transparenciainternacional.org. br/asset/54:bgc---barometro-global-da-corrupcao-2019? stream=1. Acesso em: 01 mar. 2020.

36 "Nem tudo foi exitoso e este relatório assume o compromisso de também expor e refletir sobre nossos insucessos, como o pouco avanço, durante o último biênio, de nossos programas temáticos em governança local e meio ambiente, além dos desafios ainda não superados em nossa meta de apoiar sistematicamente o ativismo anticorrupção no Brasil.” TRANSPARÊNCIA Internacional. Relatório Bianual 2017-2018. Disponível em: https://transparenciainternacional.org.br/home/relatorio-bianual-2017-2018. Acesso em: 08 mar. 2020
}

Em um contexto geopolítico em que, aproximadamente, $80 \%$ da madeira comercializada é ilegal, não se pode ignorar que a corrupção atua como fator determinante para esse mercado ${ }^{37}$. Não muito distante, estão as questões com licenciamento administrativo para exploração ambiental de grande impacto e significativas inversões econômicas ou da escolha de mercados menos exigentes e mais suscetíveis à manipulação para alocação de produtos ambientalmente danosos.

Se considerados os casos decorrentes da alcunhada Operação Lava-Jato, que se desdobrou por mais de 17 países e que, na América Latina e Caribe, foi foco destacado da Transparência Internacional, esta centrou-se em empreiteiras brasileiras que obtiveram contratos de infraestrutura bilionários nos quais burocracias e bens ambientais estavam contemplados, com pagamento de subornos e doações às eleições. Portanto, novamente a figura da opacidade dos relatórios, indicadores, rankings e documentos da Transparência Internacional é presente, perpetuando danos de difícil reparação e baixa capacidade de correção pela negação do problema em si e suas consequências.

O pagamento de propina e suborno por investidores, empreiteiras e concessionárias, em matéria de bens e serviços ambientais, não apenas desloca a legitimidade e a legalidade dos procedimentos democráticos e os primados do Estado de Direito. Contrapartidas pecuniárias espúrias e veladas para concessão, fiscalização e funcionamento de serviços ambientais criam sobrepreço para gozo de direitos humanos básicos, como é o acesso à água, ao saneamento básico e à saúde e, em típico caso de círculo vicioso, retroalimentam um modelo de corrupção primária, justificando, destarte, o índice de suborno para exercício de direitos básicos ${ }^{38}$.

Logo, por essa via, não há de se aferir, apenas, os comportamentos pessoais que admitem práticas de suborno e a ideia de cultura local destinada à corrupção ${ }^{39}$. Em determinados contextos, esse atestado é manifestação de que os custos e os entraves às políticas públicas

\footnotetext{
37 LEITÃO, Alexandra. Corruption and environmental. Journal of Socialomics, v. 5, n. 03, p. 02-03, jun. 2016.

38 "Mais de um em cada cinco cidadãos que usaram serviços públicos, tais como saúde e educação, pagou suborno no ano anterior." TRANSPARÊNCIA Internacional. Barômetro Global da Corrupção. América Latina e Caribe 2019. Disponível em: https:// comunidade.transparenciainternacional.org.br/asset/54:bgc---barometroglobal-da-corrupcao-2019? stream=1. Acesso em: 01 mar. 2020.

39 VANNUCCI, Alberto. Atlante della corruzione. Torino: Le Staffete, 2012. p. 86-87.
} 
e à fruição de direitos vertem da corrupção ambiental (entendida como prática para gozo de direitos relacionados com o meio ambiente), coexistente com a corrupção política e corporativa.

Junto aos méritos da Transparência Internacional em objetivar parametrizar a transparência e a corrupção em nível transnacional, em termos de proteção do meio ambiente, não se pode negar a opacidade dos seus relatórios, indicadores e rankings. Mesmo possuindo como apoiadores institucionais organizações de atuação na área ambiental, como é o caso da WWF e da Alliance for Integrity, deixar de mencionar a variável ambiental para o estudo da corrupção é prática que deve ser revista. No cenário da América Latina e Caribe, especialmente cria o efeito de agravar as debilidades de desigualdade social, de sonegação sistemática e contumaz de direitos humanos e de potencialização das instabilidades institucionais.

Por outro lado, é necessário reconhecer que a opacidade de indicadores transnacionais da relação entre corrupção e bens ambientais não é exclusividade da Transparência Internacional ${ }^{40}$. Em verdade, inexiste organismo de espraiamento global que tenha enfrentado esse problema com consistência e foco. Assim, a ignorância, a opacidade e o sub dimensionamento do problema leva ao seletivismo de responsáveis, ao tratamento fragmentado de possíveis soluções e canais de corrupção e baixa visibilidade que viabilizam negócios escusos, imorais e ilegais de consequências globais. Como risco, o combate à corrupção pode servir, apenas, com um embuste, como uma cortina de fumaça.

Como exemplo derradeiro, urgem serem registrados os efeitos da opacidade das ações de corrupção em matéria ambiental no Índice de Percepção de Corrupção e no Barômetro Global da Corrupção, visto que ambos, substancialmente, ignoram a variável "meio ambiente" para produção de indicadores transnacionais de transparência e corrupção. Mesmo assim, servem como insumo para produção de padrões normativos públicos, em destaque para o Compromisso de Lima, lavrado durante a $8^{a}$ Cúpula das Américas, em que, apenas e exclusivamente, no item $51^{41}$, consigna bem ambiental

40 CERVANTES, Aleida Hernández. La producción jurídica de la globalización económica. Ciudad de México: CIICH/UNAM, 2014. p. 208.

41 "51. Solicitar ao Grupo de Trabalho Conjunto de Cúpulas (GTCC) que apoie a implementação e o fortalecimento de programas nacionais, com uma perspectiva de direitos humanos, para desenvolver a capacidade da polícia, da promotoria pública, do poder (fauna silvestre) de modo extremamente fracionado e subsidiário.

Seja em nível global, seja em nível local, o necessário combate à corrupção perpassa o enfrentamento das causas, meios e efeitos da corrupção sobre bens e serviços ambientais com efetividade transnacional. Para fins de obtenção dos resultados esperados no combate à corrupção, a Transparência Internacional necessita, não obstante os méritos que possui, incluir nas métricas de percepção e barometria da corrupção, informações sobre meio ambiente e serviços ambientais, inclusive das experiências e reivindicações desde o Programa de Integridade Socioambiental (PISA). ${ }^{42}$

\section{Considerações finais}

A partir dos argumentos expostos e dos dados empíricos projetados, confirma-se a tese, segundo a qual o espaço jurídico-político-institucional de cada Estado-nacional não consegue se manter hermético para a influência de argumentos e atores transnacionais/globais. Em outras palavras, as linhas de demarcação entre o local, o nacional, o internacional, o supranacional, o transnacional e o global tornou-se vulnerável, porosa e permeável perante as dinâmicas propiciadas pelas múltiplas faces da globalização e da internacionalização de fenômenos antes estanques.

Desde seus primórdios, a globalização, por meio de suas diversas manifestações, exerce contundentes influências sobre o Direito e suas instituições. Pressiona os expedientes de produção, aplicação e execução das normas. Condiciona, desde estruturas extra, supra e transnacional, o ser e o dever-ser das instituições vinculadas ao Estado, não escapando a atividade legislativa desse fenômeno. Nesse cenário, o uso de indicadores,

judiciário e dos órgãos de controle interno, com vistas a combater os atos de corrupção, incluindo aqueles vinculados ao tráfico ilícito de drogas, ao tráfico de pessoas, ao tráfico de armas de fogo e de outras armas e ao comércio ilícito de mercadorias e de fauna silvestre." COMPROMISSO DE LIMA. 8a . Cúpula das Américas. 2018. Disponível em: http://www.itamaraty.gov.br/pt-BR/notasa-imprensa/18655-compromiso-de-lima-governabilidade-democratica-frente-a-corrupcao-declaracao-conjunta. Acesso em: 09 mar. 2020.

42 TRANSPARÊNCIA INTERNACIONAL Programa de Integridade Socioambiental. Disponível: https://transparenciainternacional.org.br/o-que-fazemos/programa-de-integridade-socioambiental. Acesso em: 10 mar. 2020. 
selos, rankings, diretrizes, códigos, certificações e afins, expedidos por atores transnacionais/globais, colabora o preenchimento de vácuos normativos, especificação nas regulamentações, condicionamento de políticas públicas e insumo para os poderes públicos nacionais.

Entretanto, a máxima compreensão dos fenômenos sintetizados para dar existência a cada indicador, além do cuidado institucional, carece ser ponderada para estabelecer estratégias à satisfação de conceitos abertos e/ou indeterminados. Noções como transparência, percepção de corrupção, honestidade, desenvolvimento humano, investimentos, compliance, accountability e outros demandam por integração e padrões de enquadramento.

Nos casos de prevenção e combate à corrupção, bem como de promoção de instrumentos de transparência, capitaneado pela Transparência Internacional, atesta-se o progressivo adensamento do debate institucional nacional pela invocação de atores e indicadores de governança transnacionais/globais. Em certa medida, dado o descrédito atribuído à classe política, os indicadores se converteram não apenas em instrumentos de mensuração e comparação, mas em ideologia para proposição de uma "boa sociedade". Percebe-se tendência de apropriação de "autoridade" das instituições transnacionais para preencher as descrenças com as "autoridades" nacionais.

Contudo, em tema absolutamente sensível como o meio ambiente, sua produção, seus bens e seus serviços, a ausência de indicadores transnacionais específicos, bem como de inocorrência de métricas atreladas à prática de corrupção, demonstra, para além da opacidade, um seletivismo sobre o combate e a prevenção à corrupção. Minimamente, incide em erro a Transparência Internacional quando não dá transparência para as origens, causas e consequências dessa fática conjugação de anseios espúrios, ilegais e imorais.

Manter a opacidade sobre a variável meio ambiente nos indicadores, relatórios e rankings de combate à corrupção fragiliza a efetividade e o sentido de engajamento da luta contra a corrupção desde a função de cada pessoa e da sociedade. É preciso assimilar que as pessoas não pagam suborno ou propina por mero deleite, mas por não haver alternativa momentânea de melhor eficácia, inclusive para questões ambientais, fato subestimado pela Transparência Internacional, ao menos nos últimos relatórios.

Manter a opacidade sobre a variável meio ambiente nos indicadores, relatórios e rankings de combate à corrupção, especialmente nos países de Modernidade tardia e com vastos recursos ambientais, alimenta um tipo específico e sofisticado de corrupção, de modo a estimular injustiças, banalizar o combate à corrupção e dar descrédito para propostas de integridade e moralidade na coisa pública.

Manter a opacidade sobre a variável meio ambiente nos indicadores, relatórios e rankings de combate à corrupção, principalmente após os recentes escândalos de fraude na emissão de gases, mineração e extração de petróleo constituíram espaços para utilização hegemônica de corporações transnacionais de condutas condenáveis no Sul Global, com base na cultura da impunidade, da fácil capilaridade de suas inversões financeiras e de concorrência desleal apta a inibir o desenvolvimento local e tributar a esses países responsabilidade central pela corrupção e por danos ao ambiente.

Assim, cabe aos poderes públicos nacionais estabelecer uma filtragem substancial quando da adoção dos respectivos indicadores em suas políticas públicas, sob pena de validar práticas perniciosas de opacidade no discurso sedutor da transparência e, com isso, fragilizar ainda mais suas instituições e seu sistema jurídico.

Por sua vez, a Transparência Internacional, em homenagem ao primado da transparência carece introduzir em seus indicadores, relatórios e rankings de combate à corrupção, métricas claras e adequadas de mensuração do impacto da corrupção sobre bens e serviços ambientais, reduzindo as insubsistências, contradições e opacidade, haja vista suas pretensões políticas globais.

\section{Referências}

CASSESE, Sabino. Chi governa il mondo? Bologna: Il Mulino, 2013.

CATANIA, Alfonso. Metamorfosi del diritto. Decisione e norma nell'età globale. Roma-Bari: Laterza, 2010.

CERVANTES, Aleida Hernández. La producción jurídica de la globalización económica. Ciudad de México: CIICH/ UNAM, 2014.

COMPROMISSO DE LIMA. 8a. Cúpula das Américas. 2018. Disponível em: http://www.itamaraty.gov.br/ pt-BR/notas-a-imprensa/18655-compromiso-de-limagovernabilidade-democratica-frente-a-corrupcao-declaracao-conjunta. Acesso em: 09 mar. 2020. 
DARNACULLETA I GARDELLA, Maria Mercè. Autorregulación y derecho público: la autorregulación regulada. Madrid: Marcial Pons, 2005.

DARNACULLETA I GARDELLA, Maria Mercè. El derecho administrativo global. Un nuevo concepto clave del derecho administrativo? Revista de Administración Pública, Madrid, n. 199, enero-abril 2016.

DAVIS, Kevin E; KINGSBURY, Benedict; MERRY, Sally Engle. Introduction: global governance by indicator. In: DAVIS, Kevin E; KINGSBURY, Benedict; MERRY, Sally Engle. Governance by indicators. Global power through qualification and rankings. Oxford: Oxford University Press, 2012.

ESPELAND, Wendy Nelson; SAUDER, Michael. The dynamism of indicators. In: DAVIS, Kevin E; KINGSBURY, Benedict; MERRY, Sally Engle. Governance by indicators. Global power through qualification and rankings. Oxford: Oxford University Press, 2012.

JESSUP, Philip. Transnational law. New Haven: Yale University Press, 1956.

$\mathrm{KOH}$, Harold Hongju. Why Transnational Law Matters. Faculty Scholarship Series, 2006, paper 1793. Disponível em: http://digitalcommons.law.yale.edu/fss_ papers/1793 Acesso em: 20 maio 2017.

LEITÃO, Alexandra. Corruption and environmental. Journal of Socialomics, v. 5, n. 03, jun. 2016.

NASSER, Salem Hikmat. Direito global em pedaços: fragmentação, regimes e pluralismo. Revista de Direito Internacional, Brasília, v. 12, n. 2, 2015.

PAUWELYN, Joost. Informal international lawmaking: framing the concep and research questions. In: PAUWELYN, Joost; WESSEL, Ramses; WOUTERS, Jan. Informal international lawmaking. Oxford: Oxford University Press, 2012.

SASSEN, Saskia. Territorio, autoridady derechos. De los ensamblajes medievales a los ensamblajes globales. Buenos Aires: Katz, 2015.

SCHEPEL, Harm. The constitution of private governan$c e$ : product standards of integrating markets. Oxford: Hart, 2005.

STAFFEN, Márcio Ricardo. Legislar por indicadores: a iniciativa legislativa brasileira anticorrupção conforme a influência de atores transnacionais. Revista de Informação Legislativa, Brasília, DF, v. 56, n. 221, p. 169-193, jan./mar. 2019.
STAFFEN, Márcio Ricardo. Superlegality, global law and the transnational corruption combat. Revista Brasileira de Direito, Passo Fundo, v. 14, n. 1, p. 111-130, abr. 2018.

STAFFEN, Márcio Ricardo; OLIVIERO, Maurizio. Transparência enquanto pretensão jurídica global. $A$ \& C-Revista de Direito Administrativo \& Constitucional, Belo Horizonte, v. 15, n. 61, p. 71-91, jul-out. 2015.

TRANSPARENNCIA INTERNACIONAL Programa de Integridade Socioambiental. Disponível em: https://transparenciainternacional.org.br/o-que-fazemos/programa-de-integridade-socioambiental. Acesso em: 10 mar. 2020 .

TRANSPARÊNCIA INTERNACIONAL. Barômetro Global da Corrupscão. América Latina e Caribe 2019. Disponível em: https:/ / comunidade.transparenciainternacional.org.br/asset/ 54:bgc---barometro-global-da-corrupcao-2019?stream=1. Acesso em: 01 mar. 2020.

TRANSPARÊNCIA INTERNACIONAL. Índice de Percepção da Corrupção. Brasil. 2019. Disponível em: https://ipc2019.transparenciainternacional.org.br/. Acesso em: 23 fev. 2020.

TRANSPARÊNCIA INTERNACIONAL. Relatório Bianual 2017-2018. Disponível em: https://transparenciainternacional.org.br/home/relatorio-bianual-2017-2018. Acesso em: 08 mar. 2020.

VANNUCCI, Alberto. Atlante della corruzione. Torino: Le Staffete, 2012.

VILLAGRAN SANDOVAL, Carlos Arturo. Soberanía y legitimidad de los actores internacionales en la reforma constitucional de Guatemala. Politica Internacional, Ciudad de Guatemala, v. 1, a. 1, p. 34-57, junio 2016. p. 39-40.

VON BOGDANDY, Armin. Common principles for a plurality of orders: A study on public authority in the European legal area. International Journal of Constitutional Law, Oxford, v. 12, n. 4, out. 2014.

VON BOGDANDY, Armin; GOLDMANN, Mathias. Taming and framing indicators: a legal reconstruction of the OECD's Programme for International Student Assessment (PISA). In: DAVIS, Kevin E; KINGSBURY, Benedict; MERRY, Sally Engle. Governance by indicators. Global power through qualification and rankings. Oxford: Oxford University Press, 2012. 
Para publicar na Revista de Direito Internacional, acesse o endereço eletrônico www.rdi.uniceub.br ou www.brazilianjournal.org.

Observe as normas de publicação, para facilitar e agilizar o trabalho de edição. 